\title{
Fungal Leaching of Heavy Metals from Sediments Dredged from the Deûle Canal, France
}

\author{
Nada Sabra ${ }^{1}$, Henri-Charles Dubourguier ${ }^{2}$, Tayssir Hamieh ${ }^{1,3^{*}}$ \\ ${ }^{1}$ Faculty of Agricultural Engineering and Veterinary Medicine, Lebanese University, Beirut, Dekwaneh \\ ${ }^{2}$ Institut Supérieur d'Agriculture de Lille, Lille Cedex, France \\ ${ }^{3}$ Laboratory of Materials, Catalysis, Environment and Analytical Methods (MCEMA-CHAMSI), Faculty of Sciences, \\ Lebanese University, Beirut, Lebanon \\ Email: ${ }^{*}$ tayssir.hamieh@ul.edu.lb
}

Received March 28, 2011; revised May 6, 2011; accepted May 29, 2011

\begin{abstract}
Filamentous fungi were used to leach heavy metals from dredged sediments in semi-pilot scale air-lift bioreactors. Prior to the bioleaching experiments, a physico-chemical characterization of the sediments comprising a sequential extraction study was conducted. The sediments turned out to highly contaminated with heavy metals. Most of the studied metals were found to be strongly linked to the matrix because of their association with the sulphides and with the organic matter. The conditions that favored the solubilization of heavy metals by the filamentous fungi turned out to be favorable for the activity of the sediments organotrophic bacterial microflora as well. The latter played a key role in the biosolubilization process by producing organic acids under temporary anoxic conditions. Better solubilization results (Mn: 77\%, $\mathrm{Zn:} 44 \%$, $\mathrm{Cu}: 12 \%, \mathrm{Cd}$ and $\mathrm{Pb}:<2 \%$ ) were thus obtained in the uninoculated sugar treatment in comparison to the fungal treatment. In general, organotrophic leaching was found to be limited by the poor nature of the organic acids and by their microbial consumption under sugar limited conditions. It was therefore restrained to the relatively mobile metals, namely those linked to the acid-soluble and reducible fractions of the sediments.
\end{abstract}

Keywords: Sediments; Heavy Metals; Depollution; Filamentous Fungi; Indegenous Organotrophic Bacteria; Sugar; Bioleaching; Organic Acids; Bacterial Acids

\section{Introduction}

The Nord-Pas de Calais region in France suffers from an important pollution of its water streams as a result of its extensive past industrial activities. Given its plane topography, large volumes of sediments are formed in the rivers every year. These sediments have to dredged periodically in order to prevent floods and navigation problems. According to the French Water Agency, more than 1 million $\mathrm{m}^{3}$ of sediments have to be dredged each year [1]. One third of this volume is polluted.

At the mean time, confined disposal is the most commonly used sediments treatment technique. It is however limited by the availability of confinement spaces and by its elevated cost. Physico-chemical techniques such as chelation or vitrification are also limited by their high costs and by the potential loss of the sediments properties [2].

Biological treatment methods are the methods of choice because they are natural, economically attractive and because they allow the reuse of the sediments after their treatment.

${ }^{*}$ Corresponding author.
Fungal leaching of heavy metals is an interesting biological treatment method $[3,4]$. It is based on the fungal production of weak organic acids that solubilize metals by forming water soluble complexes with them [5-7]. Compared to lithotrophic bacterial leaching, this technique has the advantage of being operated at mildly acidic conditions, minimizing by this way the loss of sediments properties and the eventual foaming and $\mathrm{H}_{2} \mathrm{~S}$ evolution phenomena that result from a sudden addition of strong mineral acids. On the other hand, fungal bioleaching of heavy metals is not limited by the poor solubility of some metal sulfates, namely lead sulfate [8].

Until now, filamentous fungi have been mostly been used for the leaching of heavy metals from low grade ores and mine tailings [9-11] and industrial wastes [12-14]. Very little work has been done on the bioleaching of heavy metals from complex matrices as sediments $[15,16]$. Research is needed in this field especially that it represents a treatment for polluted sediments.

Although encouraging, the obtained yield was not enough if the sediments are to be valorized after treatment. Better bioleaching yields were obtained by Chen and Lin 
[16] when using sulfur as substrate. The researchers conducted the bioleaching experiment in air lift bioreactors and operated without sediments preacification. Despite these improved results, it is important to see whether better ones can be obtained with $\mathrm{Fe}$ or with $\mathrm{Fe}^{+} \mathrm{S}$ under similar good aeration conditions (air lift bioreactors) and without an initial preacidification of the sediments. Sparrevik et al. [17] showed an importance of the sulphide binding for leaching of heavy metals from contaminated Norwegian marine sediments treated by stabilization/ solidification. On the other hand, Fang et al. [18] studied the effect of sulphur concentration on bioleaching of heavy metals from contaminated dredged sediments. Cappuyns et Swennen [19] characterized sediments during oxidation and ripening and evaluation of its potential reuse. Whereas, Rodríguez-Barroso et al. [20] studied the spatial distribution of contaminants in sediments of two rivers crossing Tangier (northern Morocco).

The aim of this paper is the fungal leaching of heavy metals from contaminated sediments. Before conducting the bioleaching studies, a physico-chemical characterization was conducted in order to determine their level of contamination as well as the speciation of the metals. The latter was studied chemically by carrying out a sequential extraction study. We have chosen the extraction scheme proposed by the European Measurements and Testing Programme previously known as the Community Bureau of Reference BCR). This scheme is in fact representative of most of the existing extraction schemes and has been validated by several interlaboratory comparesons and by certified reference materials [21]. Bioleaching experiments were conducted on a semi-pilot scale in air-lift bioreactors. The effectiveness of nutrients supplementation and fungal inoculation was studied.

\section{Materials and Methods}

The sediments were sampled from the Deûle canal situated in the Nord-Pas de Calais region in northern France. Sampling was done from a certain point of the canal, localized in the village of Haubourdin which is situated at the south of the city of Lille, the capital of northern France [1].

The sediments were digested then analyzed for their total heavy metal contents by inductively coupled plasma optical emission spectrometry (ICP-OES). For the digestion, $0.5 \mathrm{~g}$ of sediment were digested in $10 \mathrm{~mL}$ of concentrated nitric acid for 10 minutes in a microwave apparatus according to the EPA method 3051 [2]. The temperature of the samples should rise to $175^{\circ} \mathrm{C}$ in less than 5.5 minutes and remain between $170^{\circ} \mathrm{C}-180^{\circ} \mathrm{C}$ for 10 minutes and must not exceed 6 atmospheres.

Organic matter and dry suspended matter (SM) contents were determined by centrifuging the samples at 12,000 g for 25 minutes, heating the solid residue to $550^{\circ} \mathrm{C}$ and $105^{\circ} \mathrm{C}$ respectively and expressing the resulting dry weights as a function of the $105^{\circ} \mathrm{C}$ and fresh sample weights respectively.

The sequential extraction study was carried out on whole sediments according to Quevauviller et al. [21]. The sediments were air dried then sieved to $90 \mu \mathrm{m}$ prior to extraction.

Step 1: $1 \mathrm{~g}$ of dry sediment was extracted in a centrifuge tube with $40 \mathrm{~mL}$ of $0.11 \mathrm{M}$ acetic acid by shaking for 16 hours (overnight) at ambient temperature $\left(25^{\circ} \mathrm{C}\right)$.

Step 2: the residue from step 1 was rinsed with distilled water and then extracted for 16 hours (overnight) with $40 \mathrm{~mL}$ of freshly prepared $0.1 \mathrm{M}$ hydroxylamine hydrodrochloride acidified with nitric acid to $\mathrm{pH} 2$.

Step 3: the residue from step 3 was rinsed with distilled water then digested with $10 \mathrm{~mL}$ of $30 \% \mathrm{H}_{2} \mathrm{O}_{2}$, adjusted to $\mathrm{pH} 2$ - 3 with nitric acid for $1 \mathrm{hr}$ in the centrifuge tube after covering it with a watch glass. The residue was then digested for $1 \mathrm{hr}$ at $85^{\circ} \mathrm{C}$. The cover was then removed and the volume reduced to few $\mathrm{mL} .10 \mathrm{~mL}$ of the $\mathrm{H}_{2} \mathrm{O}_{2}$ solution were then added and the same digestion $\left(85^{\circ} \mathrm{C}\right.$, 1hour) and volume reduction procedure was repeated. $50 \mathrm{~mL}$ of $1 \mathrm{M}$ ammonium acetate solution adjusted to $\mathrm{pH} 2$ with acetic acid was added to the residue and the latter was extracted for 16 hours (overnight).

Shaking was done on horizontal shaking table. The sediments were continuously in suspension during the extraction. The extracts were filtered through a $0.45 \mu \mathrm{m}$ membrane prior to ICP determination.

The semi-pilot scale bioleaching experiments were conducted under non sterile conditions in 45 liters air-lift bioreactors. Three types of treatments were tested: a control, a sugar treatment and a sugar + fungi treatment (Table 1). The inoculum of the fungi + sugar treatment consisted of Aspergillus niger and Penicillium chrysogenum pellets. Two strains of Aspergillus niger (DSM 2182 and DSM 2466) and one strain of Penicillium chrysogenum (DSM 62858) were cultivated on their appropriate media until spores were obtained. These were harvested in a

Table 1. Operating conditions in the control, fungi + saccharose and saccharose treatments.

\begin{tabular}{cccc}
\hline & Control & Fungi + Saccharose & Saccharose \\
\hline $\begin{array}{c}\text { Suspended matter } \\
\text { content }(\mathrm{g} / \mathrm{kg})\end{array}$ & 28 & 30 & 36 \\
Saccharose $(\mathrm{g} / \mathrm{kg})$ & No addition & 120 & 120 \\
$(\mathrm{NH} 4)_{2} \mathrm{SO}_{4}(\mathrm{~g} / \mathrm{kg})$ & No addition & 2 & 2 \\
$\mathrm{KH}_{2} \mathrm{PO}_{4}(\mathrm{~g} / \mathrm{kg})$ & No addition & 0.8 & 0.8 \\
$\begin{array}{c}\text { Inoculation } \\
\text { percentage }(\mathrm{w} / \mathrm{w})\end{array}$ & No inoculation & $10 \%$ & - \\
Initial $\mathrm{pH}$ & Non adjusted & 6 & 6 \\
\hline
\end{tabular}


Tween 80 solution at $0.5 \%(\mathrm{w} / \mathrm{v})$ then transferred to 250 $\mathrm{mL}$ Erlenmeyer flasks which contained a filter sterilized $(0.22 \mu \mathrm{m})$ nutritive medium. The latter was composed of $120 \mathrm{~g} / \mathrm{kg}$ of sucrose, $2 \mathrm{~g} / \mathrm{kg}$ of $\mathrm{NH}_{4} \mathrm{NO}_{3}, 380 \mathrm{mg} / \mathrm{kg}$ of $\mathrm{KH}_{2} \mathrm{PO}_{4}$ and $350 \mathrm{mg} / \mathrm{kg}$ of $\mathrm{MgSO}_{4} \cdot 7 \mathrm{H}_{2} \mathrm{O}$. Its final spore concentration was adjusted to around $2 \times 10^{6}$ spores $/ \mathrm{mL}$. The spore suspension was agitated in a circular manner on an agitation table for a about a week until pellets were formed. The three types of pellets were mixed in a 1:1:1 ratio and then added to the fungi+sugar treatment at an inoculation ratio of $10 \%(\mathrm{w} / \mathrm{w})$.

The $\mathrm{pH}$ and the dissolved oxygen concentration were taken on daily basis. Samples were collected every two days. They were centrifuged at $12,000 \mathrm{~g}$ for $25 \mathrm{mn}$ at $10^{\circ} \mathrm{C}$. Both the supernatant and the solid residue were stored at $-20^{\circ} \mathrm{C}$ before analysis.

The supernatants were analyzed for their heavy metals, total sugars and organic acids contents. The heavy metals were analyzed by ICP-OES. Organic acids were analyzed by using an HPLC HyperRez column $(3.5 \mathrm{~mm} \times$ $7.8 \mathrm{~mm}$ ). The elution was achieved at $30^{\circ} \mathrm{C}$ and $210 \mathrm{~nm}$ with a solution of $\mathrm{H}_{2} \mathrm{SO}_{4} 0.003 \mathrm{M}$. The total sugars were analyzed according to the phenol-sulfuric acid method. $0.5 \mathrm{~mL}$ of a $5 \%(\mathrm{w} / \mathrm{v})$ phenol solution are added to 0.5 $\mathrm{mL}$ of supernatant in a thick walled pyrex tube. The mixture is shaken vigourously on a vortex and $2.5 \mathrm{~mL}$ of concentrated sulfuric acid are added. The resulting solution is strongly shaken again. The tube is put in a water bath at $100^{\circ} \mathrm{C}$ for five minutes then stored in the dark for 35 minutes. An orange colour develops and the absorbance is read with a spectrophotometer at $488 \mathrm{~nm}$. Cali- bration is done with standard glucose solutions ranging from 10 to $100 \mu \mathrm{g} / \mathrm{L}$ obtained from the dilution of a $1 \mathrm{~g} / \mathrm{L}$ glucose stock solution prepared in $0.15 \%(w / v)$ benzoic acid.

The solid residues were analyzed for its heavy metals and suspended dry matter content.

\section{Results and Discussion}

\subsection{Sediments Characterization}

According to Table 2, the sediments have a fine texture as the particles having less than $50 \mu \mathrm{m}$ in diameter represent more than $50 \%$ of the dry suspended matter (SM) weight. The sediments are also rich in organic matter as the organic matter percentage is greater than the mean values $(2 \%-10 \%)$ found in the sediments of the Nord Pas de Calais region.

To assess the level of contamination and in the absence of French standards specific for sediments, the total concentrations of heavy metals were compared to the French soil standards, which are values above which, no sediment or sludge application is allowed on a given soil. The sediments were not polluted by $\mathrm{Cr}$ as its concentration was below the soil standard. The contamination of the sediments was slight in the case of $\mathrm{Cu}$ but high in the case of $\mathrm{Pb}, \mathrm{Zn}$ and $\mathrm{Cd}$. Although no legislation exists at the present time for $\mathrm{Mn}$, we can notice the high load of the sediments in this metal as its concentration is superior to the Natural Values, which are values below which a given soil is considered as not polluted.

Table 2. Characteristics of the sediments dredged from the Deûle canal in the Haubourdin region.

\begin{tabular}{|c|c|c|c|c|}
\hline Parameters & French soil standards ${ }^{\alpha}$ & French sludge standards ${ }^{\alpha}$ & Natural values & Results \\
\hline$\% \mathrm{SM}^{\beta}$ (with respect to fresh sediment weight) & $-\gamma$ & - & - & 21.3 \\
\hline Particles less than $50 \mu \mathrm{m}$ as a $\%$ of SM & - & - & - & 84.5 \\
\hline$\%$ organic matter (with respect to \% SM) & - & - & - & 14.02 \\
\hline Iron (mg/kg of SM) & $-\delta$ & - & 10,000 & 24,225 \\
\hline Manganese (mg/kg of SM) & - & - & 250 & 428 \\
\hline Copper (mg/kg of SM) & 100 & 1000 & 20 & 145 \\
\hline Zinc (mg/kg of SM) & 300 & 3000 & 75 & 6014 \\
\hline Lead (mg/kg of SM) & 100 & 800 & 20 & 1222 \\
\hline Chromium (mg/kg of SM) & 150 & 1000 & 25 & 130 \\
\hline Cadmium (mg/kg of SM) & 2 & 20 & 0.5 & 475 \\
\hline
\end{tabular}

${ }^{\alpha}$ French standards as given by the decision of January $8^{\text {th }} 1998$ that figures in the French Official Journal (1998); ${ }^{\beta}$ SM: Suspended matter; ${ }^{\prime}$ No data available;

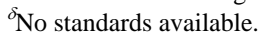




\subsection{Sequential Extraction Study}

The BCR sequential extraction scheme yields 4 major fractions which represent the main types of interactions that exist between the heavy metals and the sediments $[9,21]$. In a decreasing order of metal mobility, we distinguish:

The acid-soluble fraction or step 1 extract: it comprises exchangeable and carbonate bound heavy metals. Their mobilization is governed by acid-base equilibria.

The reducible fraction or step 2 extract: it comprises heavy metals bound to the $\mathrm{Fe}$ and $\mathrm{Mn}$ oxides and hydroxides. Their mobilization occurs under reducing conditions.

The oxidizable fraction or step 3 extract: it comprises heavy metals that are bound to sulfides and to the organic matter. Their mobilization occurs under strong oxidizing conditions.

The residual fraction: it comprises heavy metals that are strongly bound to the crystalline lattice of the sediments and which can not be released by the reagents used in the previous steps.

The sequential extraction study (Figure 1) revealed that most of the studied metals $(\mathrm{Cu}, \mathrm{Pb}$ and $\mathrm{Cd})$ are tightly linked to the matrix as they are mainly associated with the sulphides and with the organic matter fraction. $\mathrm{Zn}$ and especially $\mathrm{Mn}$ are more mobile than the rest of the metals because of their association with the acid-soluble and reducible fractions of the sediments. The heavy metals can be ranked according to a decreasing mobility order as follows:

$$
\mathrm{Mn}>\mathrm{Zn}>\mathrm{Cd}>\mathrm{Cu}>\mathrm{Pb}
$$

The predominance of the metals in the oxidizable fraction could be due to the importance of the heavy metal load. The lower the latter, the greater is the tendency to have increased residual metal concentrations [8,22]. The residual fraction reflects thus the natural geochemical background of the sediment. Besides the importance of the heavy metal load, the predominance of metals in the oxidizable fraction could be explained by the age of the pollution or by a possible redistribution of the metals from the one fraction to another during the sequential extraction procedure. Coetzee et al. [9] observed a redistribution of lead and copper as a fonction of humic acids and kaolinite in artificial sediments. This observation needs however to be validated on real sediment samples.

\section{Bioleaching Experiments}

\subsection{Saccharose Concentration}

Given the large amounts of added saccharose, the total sugar content represents mainly the total saccharose concentration. According to (Figure 2), no sucrose was noticed in the control. In the sugar treatment, a partial sugar consumption was observed although no fungi were added.
Almost $40 \%$ of the initial sugar added remains in the reactor at the end of the treatment. The observed sugar consumption is due to the activity of the sediments natural microflora. Practically all the sucrose was consumed when the sediments received a fungal inoculum. Sucrose served as a substrate for both the filamentous fungi and the sediments natural microflora.

\subsection{Dissolved Oxygen Concentration Evolution}

The dissolved oxygen concentration (Figure 3) was relatively high $(8 \mathrm{mg} / \mathrm{L}-9 \mathrm{mg} / \mathrm{L})$ in the control reactor. The concentration decreased to very low levels $(1 \mathrm{mg} / \mathrm{L}-2$ $\mathrm{mg} / \mathrm{L}$ ) in both sugar and fungi + sugar treatments. Anoxic conditions were thus established inspite the use of air-lift bioreactors. These conditions result from the important microbial activity in the presence of sugar. In the sugar treatment, anoxia was maintained until the end of the treatment because $60 \mathrm{~g}$ of sugar $/ \mathrm{kg}$ of sediment remained in the medium at the end of the experiment. Anoxia was temporary in the fungi + sugar treatment as the dissolved oxygen concentration reincreased to normal levels after the sugar has been consumed in the medium.

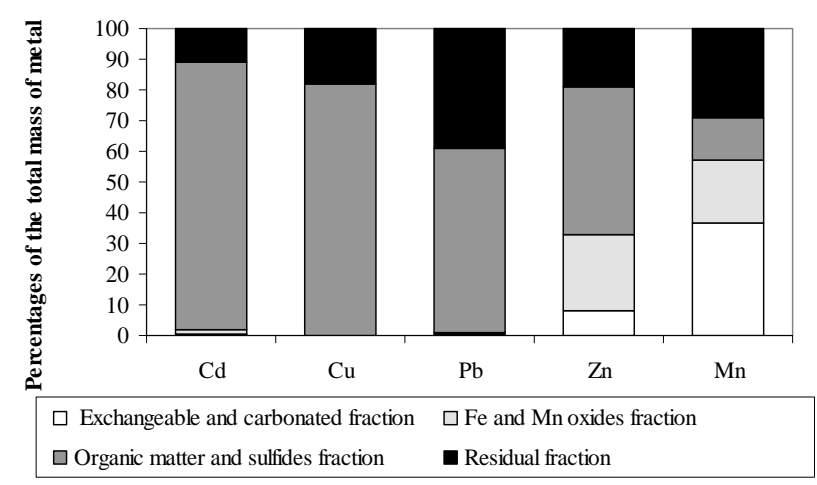

Figure 1. Heavy metals distribution in the different chemical fractions of the sediments as a percentage of the total mass of each metal.

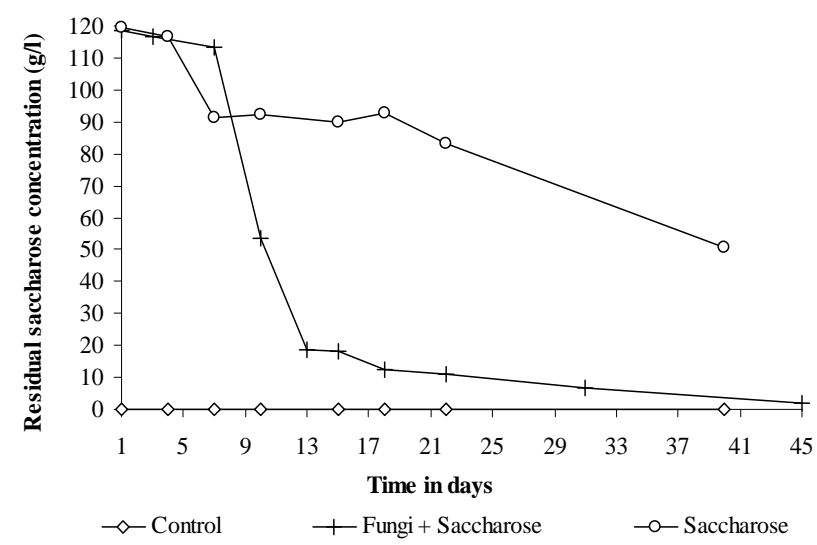

Figure 2. Evolution of the sucrose concentration in the control, fungi + saccharose and saccharose treatments. 


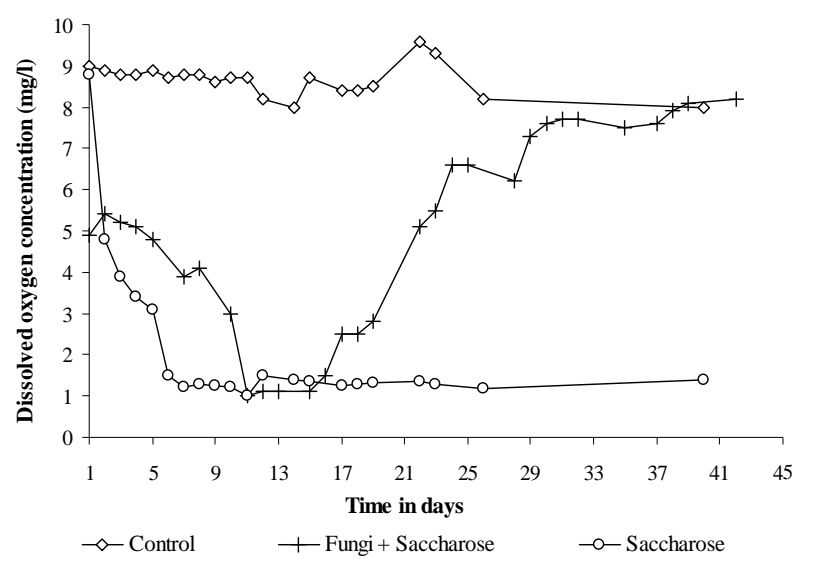

Figure 3. Evolution of the dissolved oxygen concentration in the three treatments.

\section{3. pH Evolution}

A $\mathrm{pH}$ decrease was observed in the reactors supplemented with sugar (Figure 4). The extent of the decrease depended on the residual sugar concentration in the sediments. The $\mathrm{pH}$ remained low (4.5 - 5) until the end experiment in the sugar treatment but reincreased as soon as no sugar was left in the reactor in the fungi + sugar treatment.

\subsection{Organic Acids Production}

The sugar consumption and $\mathrm{pH}$ and dissolved oxygen concentration drops were observed along with an organic acids production which accounts for the observed sediments acidification. No organic acids were formed in the control reactor. The organic matter of the sediments is thus an inadequate carbon source for acids production by either the sediments natural microflora or the inoculated filamentous fungi. Kubicek and Röhr [23] pointed out that a simple carbon source like monosaccharides or disaccharides are best suited for citric acid production by Aspergillus niger. In the sugar and the fungi + sugar treatments, gluconic acid has been formed reflecting the activity of the filamentous fungi (Figure 5). Bacterial acids namely lactic acids, acetic acid and butyric acids have also been formed. The production of these acids results from the activity of the sediments natural microflora (lactobacillus sp., clostridium sp. ...) under anoxic conditions.

The fungal acids were formed at a lower concentration in comparison to the bacterial acids. Most of the sugar and oxygen have been used by sediments bacteria to produce bacterial acids. The physico-chemical conditions have been more favorable for the activity of the sediments bacterial community, namely, the lactic acid bacteria. On the other hand, the formation of some fungal organic acids, namely citric acid, is known to be hin- dered by heavy metals $[6-8,23]$.

As for the $\mathrm{pH}$ and dissolved oxygen concentration evolution, the organic acids production is closely dependent upon the presence of sugar in the medium. Thus in the sugar treatment (Figure 6), the acids production has been practically maintained till the end of the treatment but stopped in the fungi + sugar treatment as soon as the sugar was consumed in the sediments. The disappearance of the acids with the consumption of sugar suggests that these acids have been consumed by the sediments microflora as a carbon source.

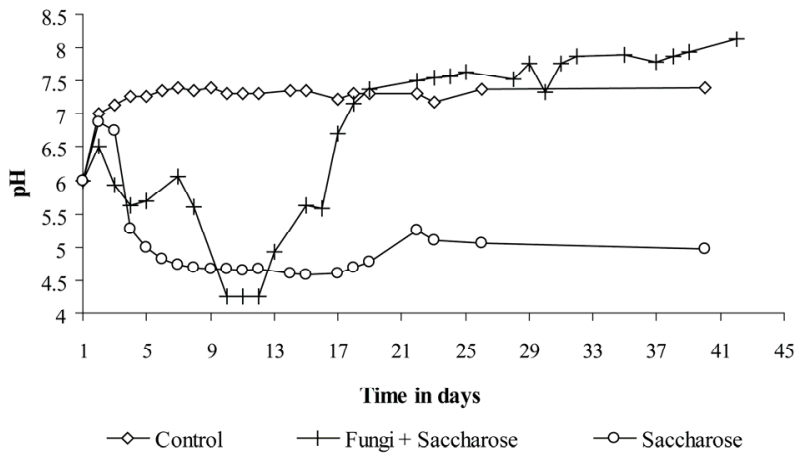

Figure 4. PH evolution in the three treatments.

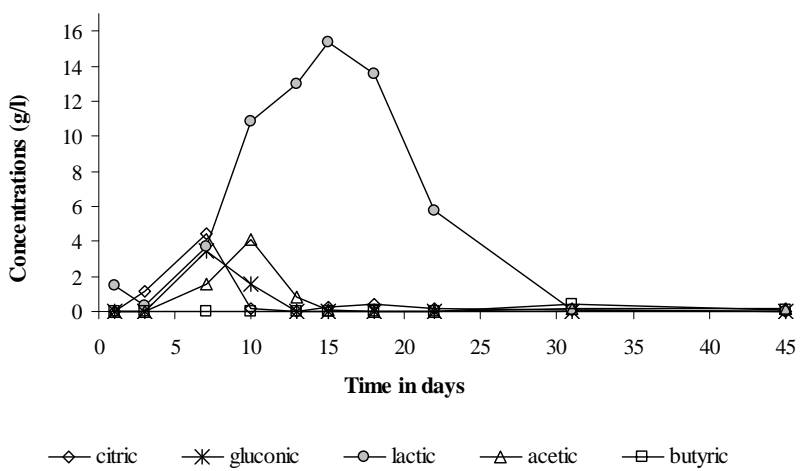

Figure 5. Organic acids production in the fungi + saccharose treatment.

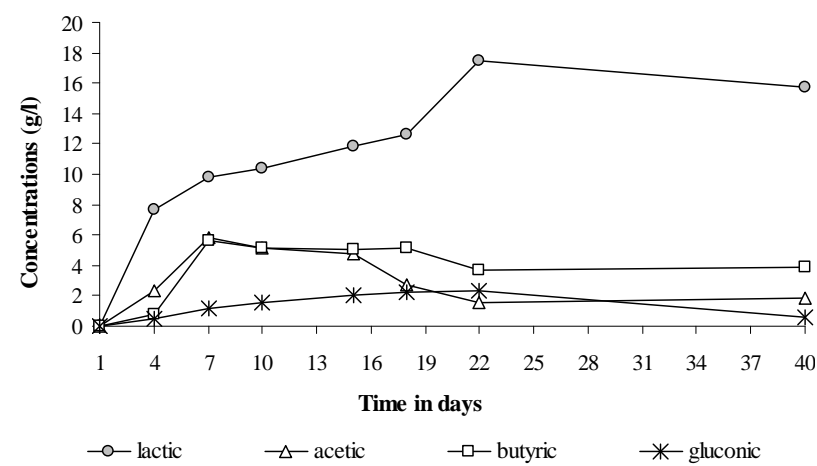

Figure 6. Organic acids production in the saccharose treatment. 


\subsection{Bioleaching Yields}

Practically, none of the studied metals was significantly leached in the control experiment. The bioleaching yields (not presented) did not exceed 5\% for each studied metal. The heavy metals are thus tightly bound to the matrix and the simple mixing and oxygenation of the sediments is not sufficient to solubilize them. $\mathrm{Mn}$ and to a lower extent $\mathrm{Zn}$ were the most solubilized metals in the sugar and fungi + sugar treatments (Figures 7 and 8). This relatively important solubilization yield is related to the association of these two metals, especially $\mathrm{Mn}$, to the acidsoluble and reducible fractions of the sediments. The bioleaching of the heavy metals is mainly brought about by organic acids through acidolysis and complexolysis $[5,6]$. Another bioleaching mechanism can be the reductive dissolution of some metals like $\mathrm{Zn}$ and $\mathrm{Mn}$ from iron and manganese oxides. This dissolution can be abiotic [24,25]. It can also be biotic: iron and manganese oxides can be reduced and thus release the attached heavy metals by heterotrophic micro-organisms that use organic acids and/or sugars as electron donors [26,27]. Low bioleaching yields were observed in the case of $\mathrm{Cu}, \mathrm{Cd}$ and $\mathrm{Pb}$ because of their lower mobility i.e. their association with the oxidizable fraction of the sediments.

The best bioleaching results were obtained in the sugar treatment. Sugar is a determinant factor in the bioleaching process. The addition of the filamentous fungi to the sediments lead to a greater oxygen and sugar consumption and thus to a more rapid organic acid depletion in comparison to sediments not inoculated with these fungi. Most of the solubilization has been carried out by the sediments natural microflora. The role of the indigenous microflora has rarely been taken into consideration in fungal bioleaching processes. As mentioned previously, filamentous fungi have rarely been used to solubilize heavy metals from sediments. The fungal leaching of heavy metals has been mainly applied to ores, mine tailings or industrial wastes and has been mostly carried out under sterile conditions excluding by this way the activity of the indeginous microflora [7,10-14,28-31]. Gupta and Ehrlich [32] worked under non sterile conditions and found that the natural microflora was less involved than the fungal inoculum in the bioleaching of heavy metals. These authors worked however on mine tailings without sugar supplementation and studied the bioleaching action of the fungal inoculum and of the natural microflora in separate experiments.

The highest bioleaching yields given by the sugar treatment were $77 \%$ for $\mathrm{Mn}, 44 \%$ for $\mathrm{Zn}, 12 \%$ for $\mathrm{Cu}, 1.6 \%$ for $\mathrm{Cd}$ and $<2 \%$ for $\mathrm{Pb}$. It is difficult to compare our results with previous studies since, as mentioned above, very little research has been done on fungal leaching of heavy metals from sediments. In a very recent study,

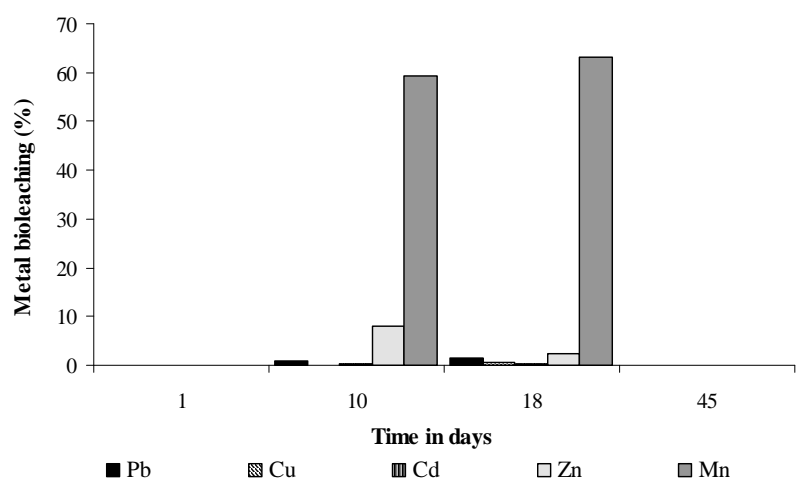

Figure 7. Bioleaching of heavy metals in the fungi + saccharose treatment expressed for each metal as a percentage of the sediment total metal mass.

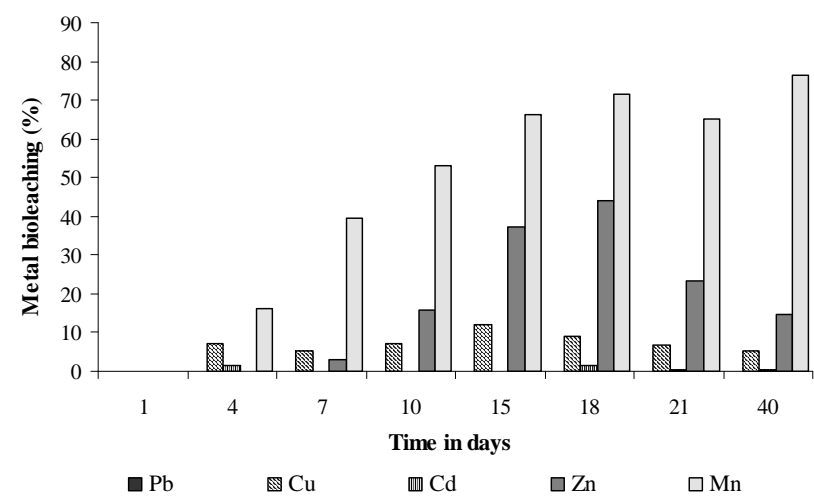

Figure 8. Bioleaching of heavy metals in the saccharose treatment expressed for each metal as a percentage of the sediment total metal mass.

Wasay et al. [33] used Aspergillus niger to bioremediate soils contaminated with heavy metals. The bioleaching yields varied from $37 \%$ to $99 \%$. The divergence of these results from ours is due to the fact that the authors worked on soils and not on sulphides rich sediments. On the other hand, the authors worked on very small amounts of soil (3.5 g - $5.0 \mathrm{~g}$ ) that were sieved and dried and with a continuous sugar supply. Furthermore, the speciation of the heavy metals was not determined in their study.

The facts that organic acids are weak acids and that they are quickly consumed by sediments microflora reduced their efficiency for the solubilization of the heavy metals that are tightly linked to the sediments. Moreover, the real potential of filamentous fungi to leach heavy metals has not been properly determined because we were under limiting sugar conditions by the end of the first week of treatment. Better solubilization results could have been obtained if we were not under these conditions, but the economic feasibility of the project would have been seriously compromised.

\section{Conclusions}

The sequential extraction scheme showed, with the ex- 
ception of $\mathrm{Mn}$, a predominant association of the heavy metals with the oxidizable fraction of the sediments.

The heavy metals could be classified by decreasing order of mobility as follows: $\mathrm{Mn}>\mathrm{Zn}>\mathrm{Cu}>\mathrm{Cd}>\mathrm{Pb}$.

The filamentous fungi were in direct competition with the sediments natural microflora for oxygen and sucrose. Most of these substrates have been used by the sediments natural microflora to produce organic acids under temporary anoxic conditions. Consequently, bacterial acids were produced in greater concentrations than the fungal acids.

Irrespective of their nature, organic acids were consumed by the sediments natural microflora as a carbon source as soon as the sucrose was depleted from the medium. The organic matter of the sediments was found to be a non suitable carbon source for organic acids production.

The organic acids formed led to a certain solubilization of heavy metals. The best results were obtained in the sugar treatment.

However, with the exception of $\mathrm{Mn}$, the bioleaching yields were relatively limited as they were less than 50\%. The treatment was suitable for relatively mobile metals that were associated with the acid-soluble and reducible fractions of the sediments.

The weak nature of organic acids and their consumption as a carbon source by the sediments microorganisms made them poorely efficient in the solubilization of heavy metals that are tightly linked to the sediments. These results could have been improved if a continuous supply of sucrose has been furnished. The economic viability of the project would however be compromised.

Better results could have been obtained with less polluted sediments or with more sandy sediments characterized by less tightly linked heavy metals.

\section{Acknowledgements}

We thank l'Agence de l'Eau Artois-Picardie, the Conseil Régional Nord-Pas de Calais and the Direction Régionale pour l'Environnement in France for their financial support of this study. Thanks are also expressed to the laboratories CREID and AGREN for conducting the heavy metals analyses.

\section{REFERENCES}

[1] Agence de l'Eau Artois-Picardie/BURGEA Région Centre-Est/CEMAGREF, "Utilisation des Oligochètes et Indices Oligochètes pour l’Évaluation du Risque Écologique lié à la Présence de Micropolluants Minéraux et Organiques dans les Sédiments du Bassin Artois-Picardie,” Rapport de Synthèse, RLy 381 a/A.5484, 1998, 1998. http://portaildoc.oieau.fr/entrepotsOAI/AEAP/26/132830/ 132830_doc.pdf.

[2] D. E. Averett, B. D. Perry, E. J. Torrey and J. A. Miller, "Review of Removal, Containment and Treatment Technologies for Remediation of Contaminated Sediment in the Great Lakes,” US EPA, Great Lake National Program Office Assessement and Remediation of Contaminated Sediment Program, Chicago, 1990.

[3] K. C. Yu, L. J. Tsai, S. H. Chen and S. T. Ho, "Chemical Binding of Heavy Metals in Anoxic River Sediments," Water Research, Vol. 35, No. 17, 2001, pp. 4086-4094. doi:10.1016/S0043-1354(01)00126-9

[4] K. C. Yu, L. J. Tsai, S. H. Chen and S. T. Ho, "Correlation Analyses on Binding Behavior of Heavy Metals with Sediment Matrices,” Water Research, Vol. 35, No. 10, 2001, pp. 2417-2428. doi:10.1016/S0043-1354(00)00518-2

[5] K. Bosecker, "Bioleaching: Metal Solubilization by Microoganisms," FEMS Microbiology Reviews, Vol. 20, No. 3-4, 1997, pp. 591-604. doi:10.1111/j.1574-6976.1997.tb00340.x

[6] W. Burgstaller and F. Schinner, "Leaching of Metals with Fungi,” Journal of Biotechnology, Vol. 27, 1993, pp. 91-116. doi:10.1016/0168-1656(93)90101-R

[7] W. Burgstaller, A. Zanella and F. Schinner, "Buffer StiMulated Citrate Efflux in Penicilium Simplicissimum: An Alternative Charge Balancing Ion Flow in Case of Reduced Proton Backflow," Archives of Microbiology, Vol. 161, No. 1, 1994, pp. 75-81. doi:10.1007/BF00248896

[8] I. Bodog, K. Polyak and J. Hlavay, "Determination of Heavy Metals in Lake and River Sediments by Selective Leaching," International Journal of Environmental and Analytical Chemistry, Vol. 66, No. 2, 1997, pp. 79-94. doi:10.1080/03067319708028353

[9] P. P. Coetzee, K. Gouws, S. Plüddemann, M. Yacoby, S. Howell and L. Drijver, "Evaluation of Sequential Extraction Procedures for Metal Speciation in Model Sediments,” Water SA, Vol. 21, No. 1, 1995, pp. 51-60.

[10] Z. Golab and B. Orlowska, "The Effect of Amino and Organic Acids Produced by the Selected Microorganisms on Metal Leaching," Acta Microbiologica Polonica, Vol. 37, No. 1, 1988, pp. 83-93.

[11] P. G. Tzeferis, "Fungal Leaching of Nickeliferous Laterites,” Folia Microbiologica, Vol. 39, No. 2, 1994, pp. 137-140. doi:10.1007/BF02906809

[12] F. Schinner and W. Burgstaller, "Extraction of Zinc from Industrial Waste by Penicillium s.p," Applied and Environmental Microbiology, Vol. 55, No. 5, 1989, pp. 11531156.

[13] B. Müller, W. Burgstaller, H. Strasser, A. Zanella and F. Schinner, "Leaching of Zinc from an Industrial Filter Dust with Penicillium, Pseudomonas and Cornybacterium: Citric Acid Is the Leaching Agent Rather than Amino Acids,” Journal of Indusrial Microbiology, Vol. 14, 1995, pp. 208-212. doi:10.1007/BF01569929

[14] W. Krebs, C. rombacher, P. P. Bosshard, R. Bachofen and H. Brandl, "Microbial Recovery of Metals from Solids," FEMS Microbiology Reviews, Vol. 20, 1997, pp. 605617. doi:10.1111/j.1574-6976.1997.tb00341.x

[15] S.-Y. Chen and J. G. Lin, "Bioleaching of Heay Metals from Sediment: Significance of $\mathrm{pH}$," Chemosphere, Vol. 44, 2001, pp. 1093-1102. doi:10.1016/S0045-6535(00)00334-9 
[16] S.-Y. Chen and J. G. Lin, "Bioleaching of Heay Metals from Contaminated Sediment by Indegenous Sulfur-Oxidizing Bacteria in Air-Lift Bioreactor: Effect of Sulfur Concentration," Water Research, Vol. 38, 2004, pp. 3205-3214. doi:10.1016/j.watres.2004.04.050

[17] M. Sparrevik, E. Eek and R. S. Grini, "Importance of Sulphide Binding for Leaching of Heavy Metals from Contaminated Norwegian Marine Sediments Treated by Stabilization/Solidification," Environmental Technology, Vol. 30, No. 8, 2009, pp. 831-840. doi:10.1080/09593330902990121

[18] D. Fang, L. Zhao, Z. Q. Yang, H. X. Shan, Y. Gao and Q. Yang, "Effect of Sulphur Concentration on Bioleaching of Heavy Metals from Contaminated Dredged Sediments," Environmental Technology, Vol. 30, No. 12, 2009, pp. 1241-1248. doi:10.1080/09593330903045115

[19] V. Cappuyns and R. Swennen, "Sediment Characterization during Oxidation and Ripening and Evaluation of Its Potential Reuse,” Environmental Technology, Vol. 30, No. 8, 2009, pp. 785-797. doi:10.1080/09593330902990071

[20] M. R. Rodriguez-Barroso, Y. Benhamou, D. Coello, B. El Moumni and J. L., Garcia-Morales, "Spatial Distribution of Contaminants in Sediments of Two Rivers Crossing Tangier (northern Morocco)," Environmental Technology, Vol. 31, No. 2, 2010, pp. 155-164. doi:10.1080/09593330903397763

[21] P. Quevauviller, G. Rauret, H. Muntau, A. M. Ure, R. Rubio, J. F. Lopez-Sanchez, H. D. Fiedler and B. Griepink, "Evaluation of Sequential Extraction Procedure for the Determination of Extractable Metal Contents in Sediments, Fresenius,” Journal of Analytical Chemistry, Vol. 349, No. 12, 1994, pp. 808-814.

[22] J. Hlavay and K. Polyak, "Chemical Speciation of Elements in Sediment Samples Collected at Lake Balaton," Microchemical Journal, Vol. 58, No. 3, 1998, pp. 281290. doi:10.1006/mchj.1997.1557

[23] C. P. Kubicek and M. Röhr, "Citric Acid Production," CRC Critical Reviews in Biotechnology, Vol. 3, No. 4, 1986, pp. 331- 373. doi:10.3109/07388558509150788

[24] S. B. Joye, M. L. Mazotta and J. T. Hollibaugh, "Community Metabolism in Microbial Mats: The Occurence of Biologically-Mediated Iron and Manganese Reduction,”
Estuarine, Coastal and Shelf Science, Vol. 43, No. 6, 1996, pp. 747-766. doi:10.1006/ecss.1996.0101

[25] P. Van Cappellen and Y. Wang, "Cycling of Iron and Manganese in Surface Sediments: A General Theory for the Coupled Transport and Reaction of Carbon, Oxygen, Nitrogen, Sulfur, Iron, and Manganese,” American Journal of Science, Vol. 296, No. 3, 1996, pp. 197-243. doi:10.2475/ajs.296.3.197

[26] J. E. Kostka and K. H. Nealson, "Dissolution and Reduction of Magnetite by Bacteria," Environmental Science and Technology, Vol. 29, No. 10, 1995, pp. 2535-2540. doi:10.1021/es00010a012

[27] P. Rusin and H. Ehrlich, "Developments in Microbial Leaching-Mechanisms of Manganese Solubilisation," Advances in Biochemical Engineering/Biotechnology, Vol. 52, 1995, pp. 1-25. doi:10.1007/BFb0102314

[28] H. Kiel and W. Schwartz, "Leaching of a Silicate and Carbonate Copper with Heterotrophic Fungi and Bacteria, Producing Organic Acids,” Zeitschrift für Allgemeine Mikrobiologie, Vol. 20, No. 10, 1980, pp. 627-636. doi:10.1002/jobm.3630201005

[29] R. Tichy, P. Lens, J. T. C. Grotenhuis and P. Bos, "Solidstate Reduced Sulfur Compounds: Environmental Aspects and Bioremediation," Critical Reviews in Environmental Science and Technology, Vol. 28, No. 1, 1998, pp. 1-40. doi:10.1080/10643389891254188

[30] W. Rulkens, "Introduction to the Treatment of Polluted Sediments," Reviews in Environmental Science and Bio/ Technology, Vol. 4, No. 3, 2005, pp. 21-221. doi:10.1007/s11157-005-2167-6

[31] R. Sierra-Alavarez, "Fungal Bioleaching of Metals in Preservative-Treated Wood," Process Biochemistry, Vol. 42, No. 5, 2007, pp. 798-804. doi:10.1016/j.procbio.2007.01.019

[32] A. Gupta and H. L. Ehrlich, "Selective and Non-Selective Bioleaching of Manganese from a Manganese-Containing Silver Ore," Journal of Biotechnology, Vol. 9, No. 4, 1989, pp. 287-304. doi:10.1016/0168-1656(89)90004-7

[33] S. A. Wasay, S. F. Barrington and S. Tokunaga, "Using Aspergillus Niger to Bioremediate Soils Contaminated by Heavy Metals,” Bioremediation Journal, Vol. 2, No. 3-4, 1998, pp. 183-190. doi:10.1080/10889869809380376 